\title{
ONDE FOI PARAR O SUJEITO? - EXPERIÊNCIAS DA SUBJETIVIDADE NA FICÇÃO DO SÉCULO XX
}

\author{
Regina Pontierl
}

Universidade de São Paulo

\section{Resumo}

Este ensaio compara duas ficções curtas: a primeira, "A marca na parede", foi escrita por Virgínia Woolf nos inícios do século XX (1917); a segunda, "Célula de identidade", de Bruno Zeni, foi publicada quase um século depois, numa antologia brasileira de novos ficcionistas. Considerando algumas semelhanças estruturais básicas, sobretudo a perspectiva narrativa e a construção da subjetividade, apontam-se diferenças a fim de enfatizar as mudanças históricas no modo como os ficcionistas tratam os problemas de seu tempo.

\section{Abstract}

This essay makes a comparison between two short fictions: the first, "The Mark on the wall", was written by Virginia Wool in the early twentieth century (1917). The second, "Cell of identity", by Bruno Zeni, was published almost one century after, in a Brazilian anthology of new fictionists. Considering some basic structural similarities, mostly the narrative perspective and the construction of the subjectivity, differences are pointed out, in order to emphasize the historical changes in the way fictionists deal with their time's problems.
Palavras-chave

Literatura

comparada;

ficção curta;

formas da

subjetividade.

Keywords

Comparative literature; short fiction; forms of subjectivity. 


\section{A ficção moderna e a hipertrofia da subjetividade}

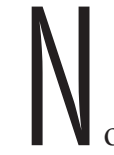

conhecido ensaio em que sintetiza a situação do romance contemporâneo, Adorno escolhe destacar a posição do narrador como momento significativo do paradoxo constituinte dessa forma. Diz ele: "não se pode mais narrar, embora a forma do romance exija a narração". ${ }^{1}$ Diferentemente do romance tradicional, ao qual o realismo era imanente, o romance moderno solaparia o preceito épico da objetividade, graças a uma subjetividade narrativa que transmuta para seus próprios termos a matéria narrável. Disso, a obra de Proust seria exemplar, já que, caudatária da tradição do realismo psicológico, leva ao extremo a dissolução subjetivista do romance, ao transformar a objetividade do mundo em vivência imaginária. Assim,

O narrador parece fundar um espaço interior que lhe poupa o passo em falso no mundo estranho, um passo que se manifestaria na falsidade do tom de quem age como se a estranheza do mundo lhe fosse familiar. Imperceptivelmente, o mundo é puxado para esse espaço interior - atribui-se à técnica o nome de monologue intérieur - e qualquer coisa que se desenrole no exterior é apresentada da mesma maneira como, na primeira página, Proust descreve o instante do adormecer: como um pedaço do mundo interior, um momento do fluxo de consciência, protegido da refutação pela ordem espaciotemporal objetiva, que a obra proustiana mobiliza-se para suspender. ${ }^{2}$

Proust é apenas um dentre os romancistas contemporâneos que se posicionam contra a "mentira da representação", que caracterizava o romance clássico, desde Cervantes, na medida em que esse romance se propunha a "provocar a sugestão do real". ${ }^{3}$ Adorno cita, ainda, o Gide dos Moedeiros falsos, o último Thomas Mann,

${ }^{1}$ Theodor W. Adorno, "Posição do narrador no romance contemporâneo", in Notas de Literatura I, trad. apres. Jorge de Almeida, São Paulo, Duas Cidades; Editora 34, 2003, p. 55.

${ }^{2}$ Idem, ibidem, p. 59.

${ }^{3}$ Idem, ibidem, p. 55. 
Musil, Kafka. Aqueles que, no século XX, são testemunhas de um processo de hipertrofia da subjetividade narrativa correlato da desintegração da "identidade da experiência, a vida articulada e contínua". ${ }^{4}$ Evidentemente, outros escritores poderiam ainda ser mencionados. Mas, em se tratando da "dissolução subjetivista" como um dos traços definidores do romance do século XX, um nome é de citação obrigatória: o de Virgínia Woolf.

De fato, a escritora garantiu seu lugar no círculo dos revolucionários da forma, graças a romances como Mrs. Dalloway, To the lighthouse, The waves, entre outros, em que a mimese do real se faz através de um ponto de vista sempre móvel e múltiplo, colado à experiência interna da personagem, a partir da qual o mundo exterior se configura, por isso mesmo, de modo fortemente impressionista. Seus dois primeiros romances publicados - The voyage out, de 1915, e Night and Day, de 1918 - possuem ainda vínculos claros com o romance inglês tradicional, embora em alguns momentos do primeiro livro já seja possível entrever a originalidade futura. Isso aconteceria a partir de 1922, com a publicação do romance Jacob's room. Antes dele, entretanto, foi fundamental a experiência de construção de um texto curto, intitulado "The mark on the wall" ("A marca na parede") que, desde sua publicação em 1917, foi considerado por contemporâneos de Woolf, como T.S. Eliot, por exemplo, como o "ponto de virada" de sua ficção em direção à renovação da forma.

\section{"A marca na parede"}

No que se refere ao mencionado processo de hipertrofia da subjetividade, "A marca na parede" é emblemático. A situação de base é a de um narrador em primeira pessoa, um eu isolado no ambiente doméstico, inteiramente fechado em si, entregue à própria consciência divagante que, movida pela visão de uma marca na parede, rememora e reflete sobre as questões mais diversas. Ao longo do texto, a subjetividade tentará descobrir a natureza da marca, aparecendo-lhe como possibilidade mais forte a de se tratar de um prego. No início se registra a recordação de um momento no passado em que pela primeira vez a existência da marca fora percebida. Antes mesmo que se tenham maiores informações sobre o eu ou sobre o espaço circundante, o que se enfatiza, desde as primeiras linhas, é a relação entre presente e passado dando suporte ao exercício da memória:

É provável que tenha sido em meados de janeiro deste ano quando pela primeira vez, olhei e vi a marca na parede. Mas para precisar a data é necessário relembrar o que vi. Assim, penso agora no fogo; na estável película de luz amarelada sobre a página do livro; nos três crisântemos no jarro de vidro redondo sobre a cornija da lareira. Sim, deve ter sido no inverno, e apenas terminávamos o chá, pois me lembro de que fumava quando olhei e vi a marca na parede pela primeira vez. $^{5}$

${ }^{4}$ Idem, ibidem, p. 56.

${ }^{5}$ Virgínia Wolf, Uma casa assombrada, trad. José A. Arantes, Rio de Janeiro, Nova Fronteira, 1984, p. 49. De agora em diante, farei referência sempre a essa tradução. No original: "Perhaps it was 
E esse exercício é tão central para a experiência relatada que o presente da enunciação, que inicialmente ainda aparece destacado do momento passado de visão da marca, aos poucos vai se fundindo a ele, a ponto de, ao final do texto, o advérbio "agora" sinalizar os dois tempos.

A partir da recuperação desse primeiro momento de visão, que é um tempo ainda relativamente próximo ao da enunciação (trata-se de "janeiro deste ano"), outros tempos, ora mais próximos, ora mais remotos, irão sendo recuperados, graças ao curso de um imaginário que passeia por vários assuntos: das ninharias do cotidiano às questões existenciais, passando pelos aspectos da vida social e cultural da Inglaterra. No exemplo a seguir, observe-se o deslizamento entre a descrição pretensamente objetiva das características da marca e a construção imaginária capaz de levar para muito longe do ponto de partida:

Sob certo ângulo de luz, a marca parece realmente projetar-se para fora da parede. Também não é inteiramente circular. Não tenho certeza, mas parece lançar uma sombra perceptível, sugerindo que, caso eu corresse o dedo pela faixa da parede, em determinado ponto encontraria a saliência de um tumulozinho, um macio túmulo como os sepulcros de South Downs, que, segundo dizem, podem tanto ser tumbas como campos. Preferiria que fossem tumbas, aspirando assim à melancolia, tal como a maioria dos ingleses; e acharia natural, ao final de um passeio, pensar nos ossos estirados debaixo do gramado... Deve haver algum livro sobre o assunto. Provavelmente algum arqueólogo desenterrou aqueles ossos e os classificou... Que espécie de homem é o arqueólogo? pergunto-me. E atrevo-me a afirmar: na maioria coronéis reformados, que conduzem grupos de trabalhadores idosos até o sítio, que examinam os torrões de terra e as pedras, e que trocam correspondência com o pároco da redondeza, a qual, aberta logo de manhãzinha, dá-lhes um sentimento de importância [...] e têm todas as razões para desejarem manter a questão da tumba ou do campo em perpétua suspensão... ${ }^{6}$

Mas essa viagem do eu em direção a camadas cada vez mais recônditas de si mesmo, camadas que, entretanto, se constituem pela matéria da vida exterior transformada pela visão, essa vertiginosa viagem vai sendo, a cada vez, pontuada

the middle of January in the present year that I first looked up and saw the mark on the wall. In order to fix a date it is necessary to remember what one saw. So now I think of the fire; the steady film of yellow light upon the page of my book; the three chrysanthemums in the round glass bowl on the mantelpiece. Yes, it must have been the winter time, and we had just finished our tea, for I remember that I was smoking a cigarette when I looked up and saw the mark on the wall for the first time" (Virginia Wolf, A Haunted House and other short stories, London, Harcourt, Inc., s. d., p. 37).

6 "In certain lights that mark on the wall seems actually to project from the wall. Nor is it entirely circular. I cannot be sure, but it seems to cast a perceptible shadow, suggesting that if I ran my finger down that strip of the wall it would, at a certain point, mount and descend a small tumulus, a smooth tumulus like those barrows on the South Downs which are, they say, either tombs or camps. Of the two I should prefer them to be tombs, desiring melancholy like most English people, and finding it natural at the end of a walk to think of the bones stretched beneath the turf... There must be some book about it. Some antiquary must have dug up those bones and given them a name... What sort of a man is an antiquary, I wonder? Retired Colonels for the most part, I daresay, leading parties of aged labourers to the top here, examining clods of earth and stone, and getting into correspondence with the neighbouring clergy, which being opened at breakfast time, gives them a feeling of importance [...] and have every reason for keeping that great question of the camp or the tomb in perpetual suspension..." (Wolf, A Haunted House and other short stories, op. cit., p. 42-3). 
pelos retornos do olhar ao exterior, sinalizado pela marca na parede. Num primeiro momento, dando-se ainda conta da forte tendência a afundar em si mesma, a subjetividade se reconforta com a volta ao mundo externo. Referindo-se a uma fantasia de infância, diz: "Para meu alívio, a visão da marca veio interromper a fantasia, pois trata-se de antiga fantasia, uma fantasia automática". ${ }^{7}$ Aos poucos, entretanto, serão cada vez mais longos os trechos de mergulho no imaginário e cada vez mais difícil o retorno à marca. Até o ponto em que, ao final do texto, a perda é total:

Onde estava eu? Falava a respeito de que? Uma árvore? Um rio? Os Downs? O Almanaque de Whitaker? Os campos de asfódelos? Não consigo me lembrar de nada. Tudo se move, tomba, escorrega, desaparece...Há uma mudança notável de assunto. ${ }^{8}$

Desde o início, o texto sinaliza, mesmo que de modo sutil, que a subjetividade divagante é a de uma mulher. O que se pode ver, por exemplo, quando ela se refere ironicamente ao

ponto de vista masculino que governa nossas vidas, que determina o padrão [...], o qual a partir da guerra, suponho, converteu-se num meio fantasma para muitos homens e mulheres, e o qual em breve, sob zombaria, espera-se, irá para dentro da lata de lixo, que é para onde vão os fantasmas...9

Confortavelmente instalada no reduto doméstico, graças ao qual se entrega ao devaneio, sem preocupações imediatas, essa mulher tem, na parede onde se localiza a marca, o ponto exato de articulação entre o espaço privado do lar e o espaço público. Não por acaso a lareira é imagem importante: a visão do fogo que ela abriga é o elemento desencadeante da fantasia, sendo a marca, que lhe fica ligeiramente acima, o elemento interruptor dessa fantasia. Sinalizando a realidade exterior à consciência, a marca, além disso, localiza-se nos confins do espaço protegido, sendo, assim, a porta de entrada para o árido mundo lá fora, ao qual a divagante se referira, indiretamente, ao mencionar a guerra. E aqui não custa relembrar que esse texto foi publicado no ano de 1917.

Aparecendo assim como símbolo da realidade objetiva, exterior à consciência, a marca acaba podendo significar também o espaço público ocupado, naquele momento, pela guerra. Não parece casual, portanto, que a divagante tenha tanta dificuldade em concentrar sua atenção na marca, sendo sempre fortemente atraída para dentro de si. O que vem, entretanto, interromper, de vez, essas fugas pelo devaneio

\footnotetext{
7 "Rather to my relief the sight of the mark interrupted the fancy, for it is an old fancy, an automatic fancy..." (Idem, ibidem, p. 37).

8 "Where was I? What has it all been about? A tree? A river? The Downs? Whitaker's Almanack? The fields of asphodel? I can't remember a thing. Everything's moving, falling, slipping, vanishing.... There is a vast upheaval of matter" (Idem, ibidem, p. 46).

9 "the masculine point of view which governs our lives, which sets the standard [...] which has become, I suppose, since the war, half a phantom to many men and women, which soon, one may hope, will be laughed into the dustbin where the phantoms go..." (Idem, ibidem, p. 42).
} 
é um acontecimento que encerra, ao mesmo tempo, o isolamento do eu e o próprio texto. Surge uma segunda pessoa que, finalmente, esclarece o que é a marca:

Alguém se inclina sobre mim e diz:

- Vou sair para comprar jornal.

$-\operatorname{Sim}$ ?

- Apesar de não ser uma boa coisa comprar jornais...Nada acontece, nunca. Essa droga de guerra. Deus amaldiçoe esta guerra...Ainda assim, não vejo porque deva haver um caracol na nossa parede.

Ah, a marca na parede! De fato, era um caracol. ${ }^{10}$

O jogo de palavras que, em inglês, aproxima "prego" (nail) de "caracol" (snail) pode sinalizar, entre outras coisas e de modo irônico, que o que se julgava como um objeto sólido o suficiente para iconizar a rigidez do mundo externo, isto é, o prego, revela-se como tão pouco firme e seguro quanto outro ser vivo. Além disso, a autossuficiência do caracol, carregando consigo a própria casa, alude fortemente ao autocentramento da divagadora, em busca de proteção na clausura doméstica. O jornal trazido de fora poderá destruir de vez qualquer segurança, testemunhando por escrito o horror da guerra ali instalada.

Referindo-se à experiência da ausência como constitutiva da ficção de Woolf, Gillian Beer chama a atenção para a importância do tema da morte nessa ficção, tema fortemente ligado à vida familiar da escritora, mas também vinculado à experiência de sua geração, no contexto da Primeira Guerra Mundial:

A morte era o seu conhecimento especial: sua mãe, sua irmã Stella e seu irmão Thoby, todos morreram prematuramente. Mas a morte era também o conhecimento especial de toda a sua geração, através da experiência obliteradora da Primeira Guerra Mundial. A longa sucessão da família e da geração, tão tipicamente o material do roman fleuve do século XIX, tais como Pendennis e The Virginians, de Thackeray, ou a série dos Rougon-Macquart, de Zola, torna-se o lugar de uma ruptura. ${ }^{11}$

Se, então, a guerra vem romper a continuidade temporal inscrita na sequência das gerações, parece claro o motivo pelo qual a divagante interrompe seu textodevaneio antes que a chegada do jornal traga a guerra, para o espaço protegido do lar. O único lugar onde, pela rememoração, é ainda possível recuperar e reatar relações com as gerações anteriores, mesmo que o olhar lançado ao passado seja, muitas vezes, de crítica a ele.

${ }^{10}$ Idem, ibidem, p. 59-60. No original: "Someone is standing over me and saying: / 'I'm going out to buy a newspaper.' / 'Yes?' / 'Though it's no good buying newspaper... Nothing ever happens. Curse this war; God damn this war!... All the same, I don't see why we should have a snail on our wall'. I Ah, the mark on the wall! It was a snail".

${ }^{11}$ Gillian Beer, "Hume, Stephen and Elegy in To the Lighthouse", in Virginia Woolf: the common ground, Edinburgh University Press, 1996, p. 31 (a tradução é minha). 
Como mostra Adorno, a ênfase no sujeito é marca forte do desequilíbrio entre eu e mundo operado pelo século XX. Entretanto, se a subjetividade woolfiana procura manter os laços com as gerações passadas, parece ser também para indiretamente apontar o antepassado ilustre a quem a escritora frequentemente homenagearia, não só por referências mais ou menos diretas em suas ficções, mas também nos ensaios que se ocuparam dele. ${ }^{12}$ Trata-se de Lawrence Sterne, "o mais genial e o mais radical" dos precursores da ficção do século XX, no dizer de José Paulo Paes, que considera Joyce, Beckett, Butor, além da própria Woolf, alguns dos que lhe sofreram o influxo. ${ }^{13}$ Parece então que o desequilíbrio entre eu e mundo, apontado por Adorno na ficção do século XX, havia sido preparado dois séculos antes pelo Tristram Shandy, que dava a ver esse processo ao encenar as vertiginosas divagações de um narrador todo-poderoso, subordinando o mundo a sua tirânica vontade.

Estudando esse romance como matriz do que conceituou como "forma shandyana", Sérgio Paulo Rouanet aponta-lhe como primeiro traço definidor a "hipertrofia da subjetividade [que] se manifesta na soberania do capricho, na volubilidade, no constante rodízio de posições e pontos de vista". ${ }^{14}$ A ele se acrescentam, como corolário, a digressividade que resulta na fragmentação do discurso, a subjetivação de espaço e tempo, além da mistura de riso e melancolia. No que se refere a Woolf, embora seja clara a presença de Sterne em seu horizonte cultural, nem por isso o diálogo com o antepassado se faz sem que a herdeira modifique o legado, imprimindo-lhe marcas próprias. De tal modo que as violentas alterações na ordem espacial e temporal, produzindo um discurso fortemente fragmentário, em decorrência da subjetividade voluntariosa do narrador shandyano, ficam em Woolf reduzidas a proporções compatíveis com os "novos" tempos. Afinal, se no século XVIII o indivíduo burguês ascendia gloriosamente à cena social, não parece mais ser tão glorioso o destino a ele reservado por um século que se abre com uma conflagração como a da Primeira Grande Guerra. De todo modo, parece claro o vulto do Tristram por detrás do narrador imaginoso e divagante de "A marca na parede". E não só porque nele Woolf inclui até uma referência à melancolia, como traço distintivo do caráter inglês. Mas, sobretudo, porque imprime a suas muitas opiniões um tom de ironia muito próximo ao do modelo.

${ }^{12}$ Ver Virginia Wolf, "The 'Sentimental Journey", in The Common Reader - first and second series. New York, Harcourt, Brace and Company, 1948. E também "Sterne" e "Eliza and Sterne", em Virginia Wolf, Granite and rainbow, London, The Hogart Press, 1958.

${ }^{13}$ L. Sterne, A vida e as opiniões do Cavalheiro Tristram Shandy, trad. introd. e notas José Paulo Paes, Rio de Janeiro, Nova Fronteira, 1984, p. 8. Paes menciona a avaliação do estudioso do Tristram Shandy, Wayne Booth, que vê na obra o ponto de partida da "grande efusão dos narradores autoconscientes do século XX", entre os quais Thomas Mann, Joyce, Hesse, Hemingway, Sartre, Butor, Durrell e outros (cf. op. cit., p. 35).

${ }^{14}$ Sérgio P. Rouanet, Riso e melancolia, São Paulo, Cia. das Letras, 2007, p. 35. Rouanet aponta quatro herdeiros da forma shandyana: o Diderot, de Jacques le fataliste, o Garrett, das Viagens na minha terra, o Xavier de Maistre, de Voyage autour de ma chambre, e o Machado, das Memórias póstumas de Brás Cubas. 


\title{
"Célula de identidade"
}

Em 1917, Virginia Woolf e sua geração estavam vivendo a primeira das duas conflagrações que atingiram e destruíram boa parte da Europa. A escritora não chegou a ver o fim da segunda dessas guerras: suicidou-se em 1942. Embora sua fragilidade psíquica já tivesse se manifestado na forma de surtos psicóticos desde os 13 anos, com a morte da mãe, não se pode menosprezar o peso de mais uma guerra nos motivos que a levaram a uma nova tentativa, desta vez bem sucedida, de tirar a própria vida.

Vista de hoje, a geopolítica mundial que se desenhou a partir do fim da Segunda Guerra gerou uma situação qualificável como de guerra permanente. De modo sumaríssimo poderíamos dizer que, primeiro, no contexto da guerra fria, as duas grandes potências produziram conflitos de várias ordens nos seus círculos de influência. Com a extinção da União Soviética, assistiu-se, no Leste Europeu, a um pipocar de guerras localizadas, nas quais os Estados Unidos tiveram presença significativa. E mais recentemente, as incursões do imperialismo norte-americano nos territórios árabes, na tentativa de proteger seus interesses econômicos, têm perpetuado o estado de guerra, fazendo dele o pão nosso de cada dia. E se assim é para os países do centro do sistema capitalista, não poderia ser melhor nas periferias. Na América Latina, onde a perversidade da exploração é secular, o desmonte do aparelho de Estado, tão caro ao triunfante projeto neoliberal, tem deixado áreas inteiras em mãos de facções criminosas, que aí impõem sua lei. De modo que, hoje, a sobrevivência diária em qualquer metrópole desta parte do mundo requer o domínio de um sem número de pequenas táticas de autodefesa. Numa avaliação muito aguda da situação atual de guerra "cosmopolita" permanente, Paulo Arantes observa que

\begin{abstract}
já não é mais possível distinguir a economia de guerra de economia de tempos de paz: vão se consolidando assim zonas formalmente em paz nas quais, todavia, grassam a violência e a criminalidade. Ao contrário da guerra clausewitziana, limitada no tempo e perseguindo dramaticamente seu desfecho fatal, as novas guerras se arrastam indefinidamente, nada é conclusivo: mais uma vez, et pour cause, a começar pela indistinção, que tende a se perenizar, entre a guerra e a paz [...] uma inovação crucial para a compreensão dos novos tempos. ${ }^{15}$
\end{abstract}

Nesse contexto, não parece casual que um representante da novíssima ficção brasileira, Bruno Zeni, tenha produzido um texto curto, intitulado "Célula de identidade" que, guardando significativas semelhanças com o de Woolf, dele se distingue em aspectos também significativos. O texto foi publicado em 2003, na antologia coletiva PS:SP. Como no de Woolf, encena-se nele o movimento de uma consciência perceptiva, num dado momento. Como ponto de referência que ancora esse movimento, no exterior, encontra-se também uma marca. Só que agora recuada para o próprio corpo: trata-se de um corte na mão. Essa imagem, cujas contínuas retomadas escandem o texto do início ao fim, está presente desde as primeiras linhas:

${ }^{15}$ Paulo Arantes, "Notícias de uma guerra cosmopolita", in Extinção, São Paulo, Boitempo, 2007 , p. 50. 
Cortei as costas da mão. Não sei como. O corte apareceu, vermelho, sangrando pouco, ardendo. Eu estava em casa, então foi em casa mesmo, em alguma quina de mesa, tampo da pia ou raspando a borda de alguma folha de papel, afiada como lâmina. Não dei muita importância, continuei fazendo o que tinha para fazer. Isso já faz uns dias, na real. Hoje olhei a mão direita e o corte, cicatrizado, me chamou a atenção. ${ }^{16}$

Como se vê, há mais semelhanças com "A marca na parede", além da presença da marca/corte. A partir do "hoje" da enunciação, a subjetividade recua a um passado próximo, em que pela primeira vez percebera o corte. Da mesma maneira, a casa é o local dessa experiência passada. Na sequência, outra semelhança aparecerá, agora com uma modificação substantiva: a subjetividade também se concentra na elaboração mental de sua experiência; só que essa se resume de modo quase obsessivo, aos episódios da guerra urbana vivida diariamente em São Paulo. Depois de, com alguma minúcia, descrever o aspecto do corte, o eu se refere à primeira matança de que se ocupará:

Faz frio finalmente, depois de um outono quente. Chove também. Na TV, vi uma reportagem sobre um homicídio na periferia de Guarulhos. Periferia da periferia. O cara apagou um outro cara por causa de 50 reais.

E o que segue são desdobramentos desses primeiros registros de violência, que se concentra pela superposição e fusão das imagens iniciais: a casualidade do aparecimento do corte ecoando na total banalidade da eliminação de uma vida humana. Diferentemente de "A marca na parede", que conseguira confinar o horror da guerra no lado de fora da consciência, da casa e do texto, encontrando desse modo amplo espaço mental para se mover por vários e amenos assuntos; agora esse horror a tal ponto constitui a vida subjetiva que tomou conta de tudo, erigindo-se em assunto único.

A essa diferença se acrescentam outras, correlatas. Assim, a casa já não protege. Nela se destacam só os possíveis instrumentos de agressão ao corpo: a quina da mesa, o tampo da pia e a borda da folha de papel, "afiada como lâmina", metáfora que também sinaliza a contundente experiência registrada, no papel-texto, justamente pela mão direita, que está cortada. Além de não proteger, a casa nem parece lugar onde se mora; nela, nem o texto se demora. O ambiente principal agora é o de uma padaria, a "padoca", espaço ao qual o "hoje", da enunciação, parece estar mais vinculado. Inclusive por ser ele o que tem maior presença no texto que, sem quebra de continuidade, passa da referência ao assassinato, à coxinha comida na padaria:

A TV botou na tela a $3 \times 4$ do morto: meia-idade, quarenta, por aí, mulato, bigode. Tava de terno na foto. O que matou tá foragido. Terminei a coxinha e o refri, pedi um café pro mano da padoca. Olhei de novo o corte. Às vezes esqueço dele, mas hoje, duas vezes, me peguei olhando a mão demoradamente, acho que admirando a cicatriz, o corte se refazendo, a forma.

${ }^{16}$ VV.AA, PS: SP, São Paulo, Ateliê, 2003. Zeni nasceu em 1975, em Curitiba. Formado em jornalismo, publicou O fluxo silencioso das máquinas, pela Ateliê, em 2002. 
O deslizamento que, da casa, desloca o foco até colocá-lo na padaria é tão sutil que não é possível saber exatamente onde acontece a passagem. Até porque o que se encontra na juntura entre os dois espaços é a TV que, como sabemos, tem hoje um lugar tão central na vida de todos que muito verossimilmente está presente tanto na casa como na padaria. E aqui surge nova e significativa diferença com relação ao texto de Woolf. Enquanto no ambiente protegido do lar tudo se concentra em torno do calor e aconchego da lareira, nessa terra de ninguém por onde transita a personagem de Zeni, a TV é o signo maior da anulação da antiga esfera privada, invadida e subjugada por uma ordem pública impessoal que não dá mais nenhuma garantia. A sequêencia de matanças que a TV escancara diante da personagem (cita-se um conhecido programa, "Cidade Alerta"), tirando-lhe qualquer distância que possibilite alguma reflexão, serve somente para reforçar a sensação de que todos estão, igualmente, à mercê da barbárie. Além disso, o modo implacável como a TV impõe sua ordem impessoal diante de uma subjetividade indefesa, agora inteiramente à mercê dessa nova configuração do espaço público, não deixa dúvidas quanto ao encolhimento do espaço reservado ao eu.

Outra mudança significativa: no texto de Woolf, a possibilidade de criar um círculo de proteção permitia até mesmo a exclusão de qualquer outra pessoa, do âmbito da intimidade do eu. Agora, o sujeito inteiramente entregue à ordem do mundo terá no seu outro uma simples repetição daquilo em que se tornaram todas as subjetividades: átomos aglutinados na massa anônima, por isso mesmo só identificáveis pelos uniformes que usam:

Olhei de novo os funcionários da padaria. Todos de uniforme. Na padoca da esquina da minha casa também é assim - todo mundo de uniforme. Teve um dia que estranhei ver um dos funcionários sem uniforme, de roupa normal. Parecia outro.

Todos bovinamente esperando sua vez de serem as vítimas do próximo morticínio. Nesse sentido, o último resquício de uma antiga e agora irreconhecível tábua de valores se mostra no rápido diálogo travado entre a personagem e o "mano da padoca", sobre o preço de uma vida humana, ou sobre o que signifique bem e mal:

O garçom pôs o café na minha frente.

- Vê se pode. O cara mata por 50 reais... Tem cara que assalta ônibus, padaria. É fraco, num pode.

Depois do intervalo, outra reportagem sobre um cara baleado no assalto de um ônibus. A TV mostrou a mancha de sangue no asfalto, as viaturas em torno, as pessoas saindo dos ônibus. [...]

- Aí, não falei? Neguinho assalta ônibus. Num pode. Tem que assaltar banco, carro forte, num é? - ele falou enquanto lavava os copos na pia atrás do balcão. [...]

- Cê mora onde? perguntei pro cara da padoca.

- Vila Selma. Atrás do shopping Interlagos. Zona Sul. [...]

- Embaçado lá?

- Não, tranqüilo. Lá não tem tiroteio, assalto a ônibus. É bom. Uma vez só, uma vez mataram três. Uns três que tentaram assaltar uma padaria.

Com relação ao texto de 1917, o de 2003 mostra, sobretudo, carência de perspectiva temporal, resultado da destruição do espaço que antes permitia a reflexão. 
Em "A marca na parede", o exercício da crítica respondia não só pelo tom de ironia das observações de um sujeito que, decidida e claramente, usava seu direito de avaliar; respondia também por um estilo feito de frases complexas, dominadas, sobretudo, pela subordinação. Em "Célula de identidade", um acúmulo de frases curtas, que quase só descrevem e constatam, apenas longinquamente apontam para um arremedo de avaliação, às vezes na forma de uma nostalgia empalidecida:

Daqui da minha janela, vejo a paisagem histórica de São Paulo lá fora, pensei. A Serra da Cantareira ainda está ao fundo, de um verde denso e intacto - dizem que é de lá que vem a água que a gente bebe. Espalhadas à esquerda e à direita, vejo algumas chaminés de fábricas. Desativadas, a maioria, mas uma ainda expele fumaça. Os carros correm na marginal, pra cá e pra lá do rio - dá para ver quando se fixa o olhar. O trânsito aéreo também é grande: aviões e helicópteros percorrem o céu, dia a dia, o dia todo. [...] Há as casas mais antigas, para os lados da Lapa, mas fizeram também umas torres de escritórios novas - o capital avança - na Barra Funda.

Significativamente, a dimensão temporal histórica se espacializa, transformando-se em paisagem; e se naturaliza, confundindo-se com o verde da serra. O universo onde vive o anti-herói de Zeni sofreu um gigantesco encolhimento. Destruiu-se o passado e com ele a visão em perspectiva e o manancial onde buscar as formas de organizar a experiência. Resta um presente achatado que se descortina à janela como pura superfície. E mais: se a marca/corte, como fronteira entre dois espaços, recuou para o corpo, agora transformado em parede, onde teria ido parar o eu em fuga? Entrincheirou-se, talvez, no microespaço da célula, último reduto da identidade?

\section{As metamorfoses do sujeito (à guisa de conclusão)}

Também no Tristram Shandy a guerra comparece como contraponto, no espaço público, da esfera privada de Shandy Hall, a casa do pai de Tristram, a partir da qual o narrador desenrola as inúmeras histórias encartadas na história principal, a de seu nascimento. Uma delas é a de Toby, seu tio, cujos lances acompanham sua participação em alguns episódios da Guerra de Sucessão da Espanha. Ferido, Toby é obrigado a se afastar dos campos de batalha, com o que muito se entristece, fortemente dedicado que é às atividades bélicas. Para confortá-lo, seu criado de quarto constrói-lhe uma réplica daqueles campos, passando Toby a "brincar" de fazer guerra. Como consequência de tal redução da importância da guerra, Rouanet aponta a desmaterialização da história real que se torna abstrata e vazia: "concretas são apenas as maquetes com que Toby a representa. Ela é miniaturizada, cabendo no fundo de um quintal. Impossível desvalorização mais contundente". ${ }^{17}$ Tão grande é a força da esfera da subjetividade que, correlata à hipertrofia do plano individual, ocorre uma espécie de atrofia do âmbito público da guerra, transformada em simples brincadeira de adultos.

O sujeito de "A marca na parede", embora ainda hipertrofiado, deve entretanto disputar com o mundo um espaço que a presença incontornável de uma parede

\footnotetext{
${ }^{17}$ Rouanet, Riso e melancolia, op. cit., p. 122.
} 
diante dos olhos revela já estar francamente tomado pela guerra. No final do processo, o texto de Zeni encena uma subjetividade em estado de atrofia que apenas espelha a realidade da guerra, incapaz de refletir sobre ela. Aqui, como no Tristram Shandy, só que por motivos opostos, esvazia-se a história real, agora transformada em paisagem.

Comentando a alteração sofrida pelo romance a partir de Proust, no que se refere à distância estética, Adorno observa que enquanto no romance tradicional essa distância era fixa, será agora variável "como as posições da câmara no cinema”. Nesse processo, ele reserva a Kafka um papel especial:

O procedimento de Kafka, que encolhe completamente a distância, pode ser incluído entre os casos extremos... [...]. Por meio de choques ele destrói no leitor a tranqüilidade contemplativa diante da coisa lida. Seus romances [...] são a resposta antecipada a uma constituição do mundo na qual a atitude contemplativa tornou-se um sarcasmo sangrento, porque a permanente ameaça da catástrofe não permite mais a observação imparcial, e nem mesmo a imitação estética dessa situação. ${ }^{18}$

Em "A marca na parede", o sujeito em guarda contra o mundo encontra no caracol o modelo para sua busca de proteção, redobrando-se para dentro de si mesmo. Em "Célula de identidade", não há mais proteção possível, nem mesmo no nível da pele, pois a marca/corte aí instalada tem, como diz o texto, "a forma de um escorpião", o corpo sendo, ele próprio, o lugar da violação do eu.

Entre o caracol, criatura que a alguns talvez repugne mas que não apresenta perigo, e a clara ameaça de um escorpião, não há como não lembrar o inseto claramente repugnante, embora ainda também não ameaçador, em que se vira transformado Gregor Samsa, ao acordar, uma bela manhã. Parece que o processo de reificação, que em Woolf, Kafka e Zeni responde pela aproximação do humano a formas animais cada vez mais ameaçadoras, vai num crescendo. A personagem de Zeni é fruto de uma época em que, no dizer de Christopher Lash

a preocupação com o indivíduo [...] assume a forma de uma preocupação com a sobrevivência psíquica. Perdeu-se a confiança no futuro. [...] Desde o término da Segunda Guerra Mundial, o fim do mundo assomou como uma possibilidade hipotética, mas nos últimos vinte anos, a sensação de perigo cresceu ainda mais... [...] O risco de desintegração individual estimula um sentido de individualidade que não é "soberano" ou "narcisista", mas simplesmente sitiado. ${ }^{19}$

Assim, do texto da escritora inglesa, ao do brasileiro, parece possível ler o processo já concluso de instalação da barbárie, deixando para trás o tempo em que a catástrofe era apenas uma ameaça.

18 Adorno, "Posição do narrador no romance contemporâneo", op. cit., p. 61.

${ }^{19}$ Christopher Lash, O mínimo eu, trad. João Roberto Martins Filho, São Paulo, Brasiliense, 1986, p. 9-10. Fazendo de William Burroughs um de seus exemplos, Lash diz que esse escritor "toma como tema não o eu soberano de uma tradição literária anterior, mas o eu sitiado, programado e sob controle" (Idem, ibidem, p. 123). 